\title{
INNOVATIVE APPLICATIONS OF ACOUSTIC WAVES FOCUSATORS
}

\author{
S.R. Abulkhanov ${ }^{1}$, D.S. Goryainov ${ }^{2}$ \\ ${ }^{1}$ Samara National Research University, Samara, Russia, \\ ${ }^{2}$ Samara State Technical University, Samara, Russia
}

\begin{abstract}
Here, we propose and investigate designs for devices which use acoustic wave focusators. We have modeled the processes involved by use of the ANSYS software. This was done in order to demonstrate the efficiency of diffractive acoustic elements for mixing particles of different densities and for damping high-frequency vibrations. The proposed designs and technological solutions could be used effectively for mixing reactive substances of various fractions and for damping the effects of high-frequency vibrations on precise measuring instruments.
\end{abstract}

Keywords: focusators of acoustic waves, acoustic diffractive elements, numerical modeling, mixing system, damping system of high-frequency vibrations.

Citation: Abulkhanov SR, Goryainov DS. Innovative applications of acoustic waves focusators. CEUR Workshop Proceedings, 2016; 1638: 173-184. DOI: 10.18287/1613-0073-2016-1638-173-184

\section{Introduction}

Acoustic technologies are used extensively in various branches of science and technology [1-3]. For example, acoustic logging is used when exploratory geological work is undertaken [4].

In this article we suggest using "backlog" - which was developed at the Image Processing Systems Institute of the RAS (IPSI RAS) [5] for laser radiation focusing [6-8] -for acoustic wave focusators instead.

The design and technological groundwork revealed the efficiency and the operability of the laser radiation focusators for branding, thermal processing, cutting and monitoring of various parameters, etc. [6-12]. Laser radiation focusators have been under development for the last 35 years, and their use in investigations has led to a large number of different methods being worked out in respect of this use: asymptotic [1315], iterative [16-17], and numerical [18-19] methods of analysis; conformable software for design [20-23] and modeling [24-28], polymeric [29], plasmachemical [3033], mechanical [34],and laser [35-36] methods of production, also instrument facilities and experimental exploratory procedures [37-40]. 
Research work [8] has demonstrated the possibility of applying diffraction acoustic elements (DAE) to the mixing of components of various dimensions, and for damping high-frequency vibrations. However, the work [8] does not present any data which confirms the introduced design's operability.

The purpose of this article is, essentially, the numerical simulation of our designs for the corroboration of this design's operability, and in order to determine the operating conditions of the vibromixer and damper.

\section{Problem formulation}

The problem of mixing various fractions of particles occurs in many economically important branches of technology: powder metallurgy [41], bubbling and mixing of the solid particles in reactors for fine chemical manufacture [42], in construction materials production [43], agriculture [44], et al. The distinguishing characteristics of these mixing operations are their operation at high energy intensities and the requirement to use costly equipment. For all these reasons, existing techniques related to this kind of mixing operation are unacceptable for many engineering problems: for example, in the small agriculture sector. Thus, at this time, there are many new engineering problems which demand new solutions. Fine-dispersed substance mixing (including nanoparticle mixing) faces the challenge of particle "agglutination". At present, there is no effective technique which can effect the mixing of microparticles in an economically viable time.

High-frequency vibration damping is a topical problem in precision mechanical and instrument engineering. At present, active damping systems are considered to be the most effective [45-46]. However, these systems are insufficiently failsafe due to the large number of components of which systems such as this comprise. The development of an inexpensive and failsafe damper design, which is capable of diffusing the energy of the high-frequency harmonic components of vibrations, would be useful for many industry sectors: mechanical engineering, instrument engineering, fine chemical production et al.

\section{Testing technique}

The detection of the capacity for momentum impartation of particles inside the receptacle, via the bottom vibration, was carried out by use of the ANSYS Workbench software. The receptacle was assumed to be an axisymmetric receptacle with a cylindrical form. The inner diameter of the receptacle base was $90 \mathrm{~mm}$ and the wall thickness was $2.2 \mathrm{~mm}$; the receptacle height was $100 \mathrm{~mm}$. For the receptacle wall, the material that was chosen was cast iron (State Standard 1412-85: Cast iron with the vermicular graphite); this has a high vibration energy absorption coefficient and is reasonably priced. Steels and alloy materials of domestic manufacture are absent from the ANSYS software library of materials; therefore, the foreign analog of the cast iron, GG-30 (DIN 1691), was used for the calculation. 
It was assumed that all the particles, involved in the mixing process, were spherical in form, and all had an outer radius of $8.25 \mathrm{~mm}\left(\mathrm{R}_{\mathrm{sph}}=8.25 \mathrm{~mm}\right)$. On the other hand, density and elastic properties could be of two types. The density of the solid spheres corresponded to the packed density of granulated polycarbonate (700 kilograms per cubic meter), and the elastic properties corresponded to those of monolithic polycarbonate (compression modulus of elasticity $\mathrm{E}=2400 \mathrm{MPa}$, Poisson's ratio- 0.39). This selection of density values and sphere elasticity properties was made in order to coincide with those of pelleted mixed feed density and elasticity properties (GOST R 51899-2002 Pelleted mixed feed). The vibromixer is intended to be used for agricultural purposes.

Not only solid spheres, but also hollow spheres were used in the mixing operation. The hollow sphere's material corresponded to the chosen polycarbonate properties. But the inflexibility (the capability to resist deformations) of the hollow spheres differed from the solid sphere's relative inflexibility. The modeling process allows for the mixing of spheres with various inflexibilities, and the numerical model is approximated to the real mixing process. The wall thickness of the hollow spheres was $3.25 \mathrm{~mm}$

The simulation of the damping process included solid titanium spheres only (the properties of solid titanium, as represented by the ANSYS database, correspond to the properties of the real world material to which this study relates). The damping, housing and physical-mechanical properties corresponded to the vibromixer receptacle characteristics.

For the real world vibromixer design, it was proposed that the vibration source should generate vibrations with a frequency of $100 \mathrm{~Hz}$, and an amplitude of $1 \mathrm{~mm}$. Vibration modeling was effected by segmenting the receptacle base, these segments moved apart from each other under the sine law.

The modeled mixing process was carried out for $1.5 \mathrm{sec}$. The required computing time was 24 hours.

\section{Vibrating mixer}

The vibrating mixer design [47-48] was examined in order to demonstrate the advantages of using diffraction acoustic elements.

The vibromixer design, for agricultural purposes, is shown in figure 1. In this case, components with five different dimensions (fractions) and inflexibilities are mixed.

The mixing process of the components, 5 , is the result of the rippling effect of the vibrator, 2, which generates acoustic spectrum vibrations. Vibrations are transmitted through the diffuser, 3 , to the operating surface of the DAE, 4. The Vibratory-active surface of the diffraction acoustic element, 4,concentrates acoustic waves to the circles on the conical surface by the use of distinct elements in the form of Fresnel circles. Particles of the mixing components, 5, placed on the conical surface, receive some kinetic energy; consequently, a "reduced" layer of the particles, of component 5, is formed on the conical surface. Particles of component 5 , having a certain ratio of dimensions and distances between adjacent circles on the conical surface, roll down 
along the conical surface. The mixing particles of components 5 from the upper layer then take their place. The design of the receptacle, filled with spheres, was examined in the ANSYS software in order to check the efficiency of the vibromixer operation. The DAE microrelief was applied on the receptacle base.

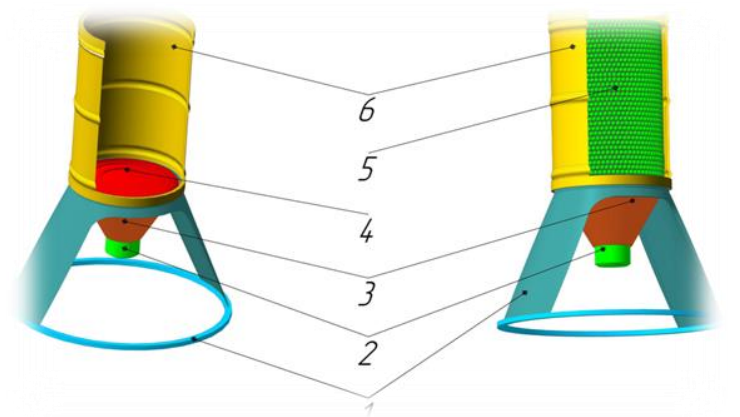

Fig. 1. Vibrating mixer (agricultural version): 1 - stanchion; 2 - vibrator; 3 - diffuser; 4 diffraction acoustic element; 5 - mixing components; 6 - receptacle

The evolution of the mixing of the spheres with various inflexibilities in 1.5 seconds is shown in figure 2. Figure 2a presents the mixing process at time $t=0.4$ seconds after mixing was started. Figure $2 \mathrm{z}$ presents condition time $t=1.5 \mathrm{~seconds}$ after mixing was started. Figures $2 \mathrm{~b}-2 \mathrm{f}$ presents the interim conditions at intervals of 0.25 seconds.

The evolution of the spheres, in terms of repositioning, indicates the effectiveness of the mixing process. The model tests showed that effective mixing is realized with a certain ratio of sphere (component 5) dimensions to wavelength (of the longitudinal acoustic radiation):the nearer the vibration wavelength is to the particle's diameter, the less time is required for the mixing.

It became apparent that heavy spheres (in component 5) were able to move down to the base, 4 , of the receptacle, 6 , and, when the sphere then received an impulse, would be able to force out a minimum of two lighter spheres from above. This action of the heavy spheres needs the acoustic radiation wavelength value to be very close to the sphere's diameter. It should be noted that the diameter of the spheres (in 5) should not be a multiple of the diameter of the receptacle; otherwise jamming of the spheres in one horizontal line can take place. This jamming could decrease mixing efficiency. Asymmetrical disposition of cut of the receptacle, 6, in the horizontal plane obviates these difficulties (i.e., the jamming of the mixing spheres, 5).

It should be noted that the mixing of powders with nanodimensions is possible, using this design, provided that the necessary acoustic wavelength is obtainable. The use of diffraction acoustic elements makes it possible to mix particles of various fractions inside a hermetic receptacle. This condition is reliable for operation with reactive substances.

The vibromixer design is patented [47-48]. Attributes of the design are as follows: a low expenditure of energy, manufacturability and reliability. 
a)

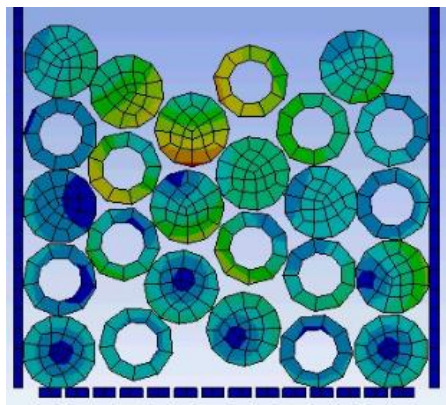

c)

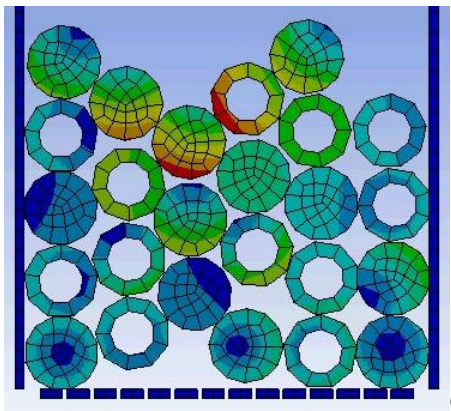

b)

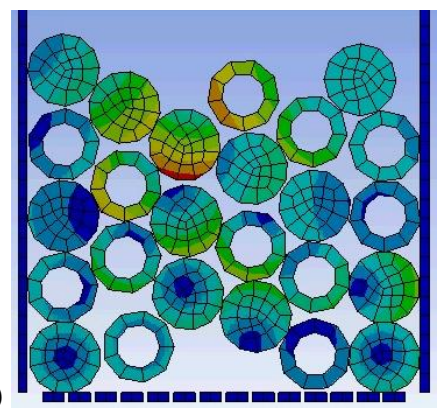

d)

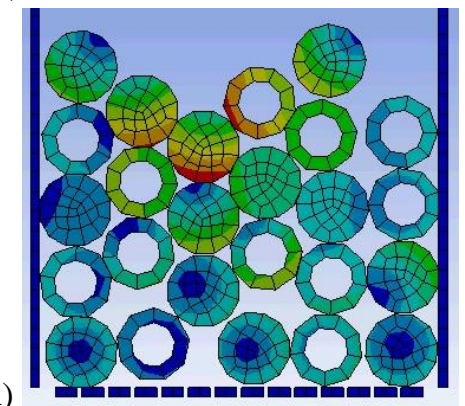

e)
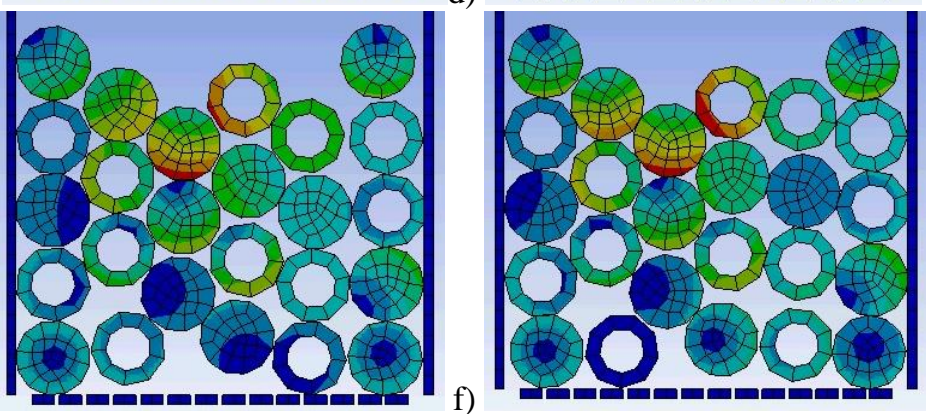

g)
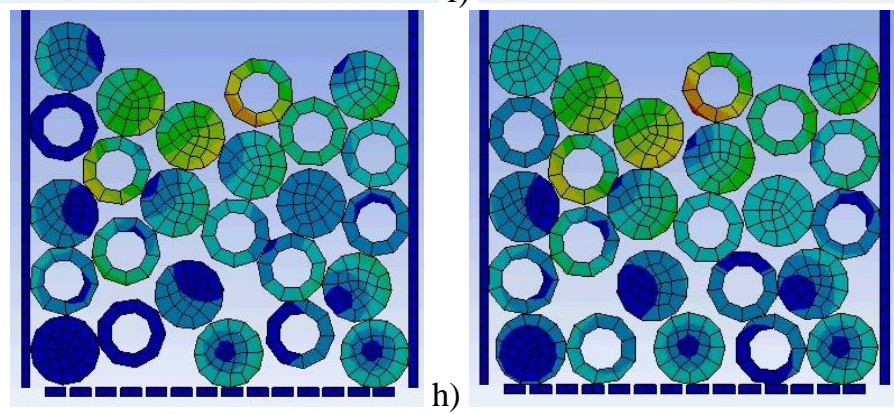

Fig. 2. Evolution of the mixing of the spheres of one radius, but variable densities and elastic properties (starting time $t=0.4$ seconds, time interval of the fixing of the sphere location in the receptacle -0.25 seconds) 


\section{High frequency damper}

High frequency irregular vibrations are rarely isolated during the carrying out of highfrequency operations. Impulse vibration stresses occur in machine-tool building and instrument engineering -for example, when the tool falls down accidentally; in terms of guidance systems, the vibrations could be from a geological source or they could be vibrations from the operating equipment.

A high frequency damper [49] is proposed which will decrease the influence of these irregular impulses upon high-frequency systems operation. The engineered design makes it possible to damp high-frequency vibrations via vibration energy dissipation (figure 3). For this purpose, vibrations encountered by the high frequency damper are passed from the base, 1, to the diffraction acoustic element, 4, with microrelief which focuses the vibration energy onto the spheres, 5. The focus of DAE 4 has to be located outside of the damper's cover, 3. The spheres, 5, start to interact chaotically with each other as a result of the vibration influence from the damper base, 1, and energy dissipation of the impulse vibrations occurs. The spheres, 5, occupy no more than half of the capacity of the bushing, 2, while simulating the damping process(fig. 4). This damper design is patented [49].

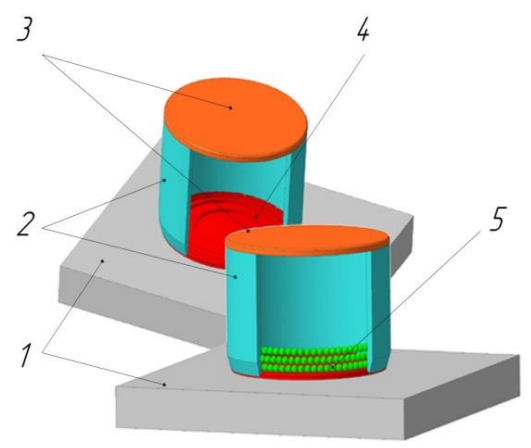

Fig. 3. High frequency damper design: 1 - base, 2 - cylindrical bushing of the damper, 3 cover, 4 - diffraction acoustic element, 5 - spheres.

Figure 4 shows the evolution of the mixing of the titanium spheres, 5, via acoustic vibrations of the damper base, 1 , over 1.5 seconds. Figure 4 a presents the damping process at time $t=0.4$ seconds after mixing has started. Figure $4 \mathrm{~h}$ presents condition time $t=1.5$ seconds after mixing was started. Figures $4 \mathrm{~b}$ to $4 \mathrm{f}$ present interim conditions at intervals of 0.25 seconds.

From figure 4, we can see that the acoustic energy dissipation of the base, 1, through the spheres, 5, occurs with sufficient efficiency. The more weight the spheres have, the more inert is the damper's response to vibrations: i.e. the longer the vibration wavelength is, the more weight the damper spheres should have.

Numerical experiments showed that the less weight the spheres have, the more dynamic the damper operation is (the less the starting time of the spheres is). The damp- 
er could be customized to the filtration of vibrations of specific frequencies by changing the weight of the spheres in 5 .

a)
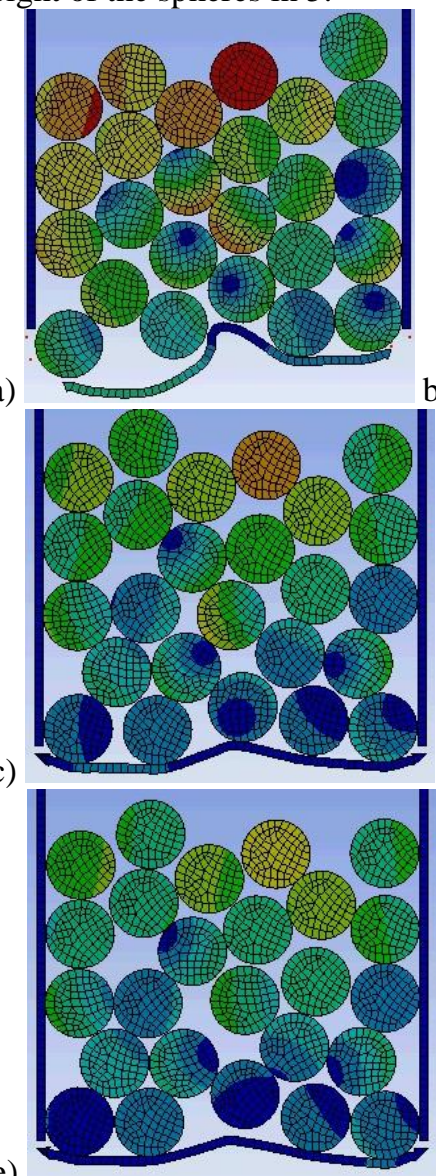

e)

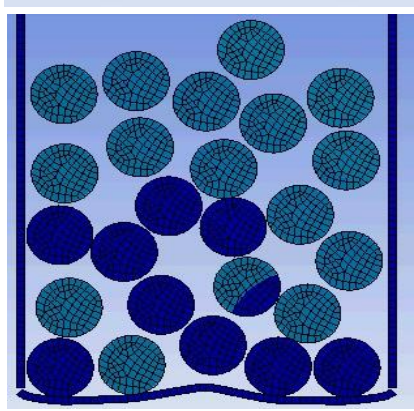

b)

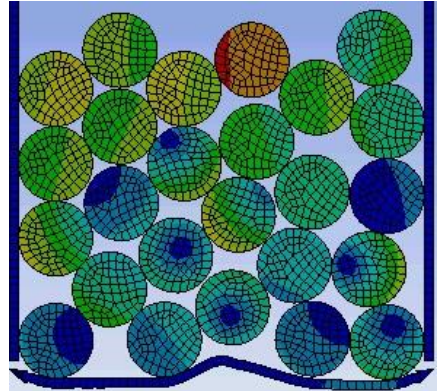

d)

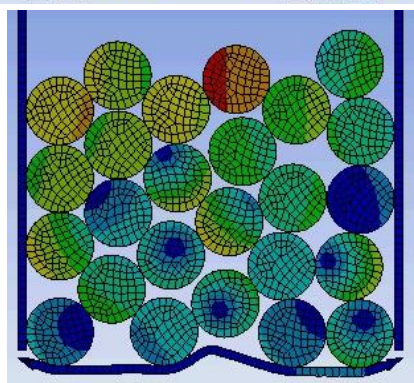

f)
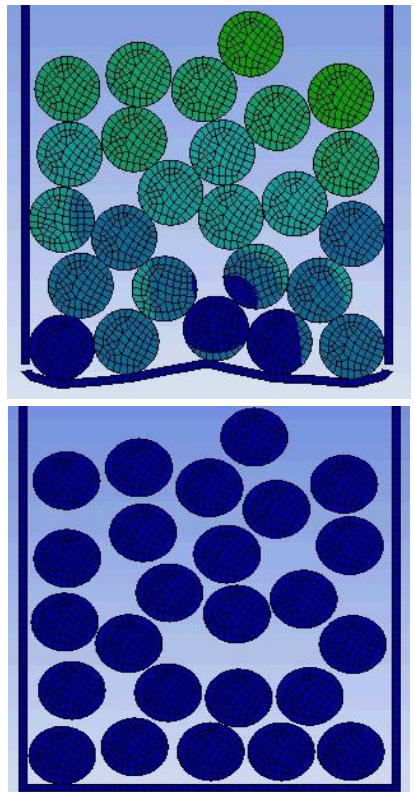

Fig. 4. Evolution of the mixing of the spheres of the same radius, density and elastic properties (starting time $t=0.4$ seconds, time interval of the fixing of the sphere location in the receptacle -0.25 seconds) 
The ability to fill the cylindrical bushing, 2, by spheres (from 5)with various forms, dimensions, and densities, along with the ability to change the quantitative ratio of the various fractions of the damping elements (spheres, 5) make it possible to damp impulse vibrations selectively. Because of this, new manufacturing capabilities, for example, liquid emulsifications and others are opened up.

\section{Conclusion}

In this article we proposed two designs: that of a vibromixer and that of a high frequency damper. We proposed a methodology for the identification of reasonable design solutions in relation to the vibromixer and the high frequency damper design process. This methodology used the ANSYS software.

Designs, similar to the vibromixer's, could be used for liquid emulsification.

The simulation of the mixing processes of particles with various densities in the ANSYS software demonstrated the efficacy of using a diffraction acoustic element for this. Also, it was found that using a DAE for the damping of high frequency vibrations resulted in an acceptable level of damping of certain harmonic components of the vibration spectrum.

Using the "backlog" - developed at the Image Processing Systems Institute of the RAS (IIPS RAS), for use in the field of optical instrument engineering [50-64] and diffraction nanophotonic [65-74] - for the designing of diffraction acoustic elements with certain characteristics would seem to be a very promising direction for future work.

\section{References}

1. Gulyaev YV, Nikitov SA, Suchkov SG, Yankin SS, Suchkov DS, Plessky VP. SAW radio-frequency identification tag for the $6-\mathrm{GHz}$ band. Journal of Communications Technology and Electronics, 2015; 60 (4): 402-405.

2. Afanas'ev AM, Pustovoǐt VI. Wave Diffraction on a Periodic Structure with an Arbitrary Spatial Variation of the Medium's Properties. Doklady Physics, 2003; 48(9): 501504.

3. Pustovoit VI. Acousto-optical properties of metamaterials. Quantum Electronics, 2016; 46(2): 155-158.

4. Kazanskiy NL, Serafimovich PG, Kharitonov SI. Adaptive iterative algorithm for the allocation of various types of waves in acoustic logging data. Computer Optics, 2001; 22: 41-46 [in Russian].

5. Kolomiets EI. Analysis of the scientific and organizational results of the Image Processing Systems Institute of the RAS. CEUR Workshop Proceedings 2015; 1490: 309326. DOI: 10.18287/1613-0073-2015-1490-309-326.

6. Golub MA, Sisakian IN, Soifer VA. Infra-red radiation focusators. Optics and Lasers in Engineering, 1991; 15(5): 297-309.

7. Abul'khanov SR. Technologies of laser radiation focusators. Research Journal of Applied Sciences, 2014; 9(11): 834-842. 
8. Abul'khanov SR. Technological applications of focusing optical elements. Proc. SPIE. Optical Technologies for Telecommunications, 2014 (March 25, 2015); 9533: 95330B. DOI: $10.1117 / 12.2180564$

9. Doskolovich LL, Kazanskiy NL, Kharitonov SI, Usplenjev GV. Focusators for laserbranding. Optics and Lasers in Engineering, 1991; 15(5): 311-322. DOI: 10.1016/01438166(91)90018-O.

10. Doskolovich LL, Golub MA, Kazanskiy NL, Soifer VA, Usplenjev GV. Diffractive optical elements for laser processing. Proceedings of SPIE 1993; 1983(2): 647-648.

11. Kazanskiy NL, Murzin SP, Tregub VI. Optical system for realization selective laser sublimation of metal alloys components. Computer Optics, 2010; 34(4): 481-486.

12. Kazanskiy NL, Murzin SP, Osetrov YeL, Tregub VI. Synthesis of nanoporous structures in metallic materials under laser action. Optics and Lasers in Engineering, 2011; 49(11): 1264-1267. DOI: 10.1016/j.optlaseng.2011. 07.001.

13. Golub MA, Kazanskii NL, Sisakyan IN, Soifer VA. Diffraction calculation for an optical element which focuses into a ring. Optoelectronics, Instrumentation, and Data Processing, 1987; 6: 7-14.

14. Kazanskiy NL, Kharitonov SI, Soifer VA. Application of a pseudogeometrical optical approach for calculation of the field formed by a focusator. Optics \& Laser Technology, 1996; 28(4): 297-300. DOI: 10.1016/0030-3992(95)00103-4.

15. Kazanskiy NL. Asymptotic research in computer optics. CEUR Workshop Proceedings, 2015; 1490: 151-161. DOI: 10.18287/1613-0073-2015-1490-151-161.

16. Kazanskiy NL, Kotlyar VV, Soifer VA. Computer-aided design of diffractive optical elements. Optical Engineering, 1994; 33(10): 3156-3166.

17. Doskolovich LL, Kazanskiy NL, Soifer VA. Comparative analysis of different focusators focusing into a segment. Optics and Laser Technology, 1995; 27(4): 207-213.

18. Kazanskiy NL, Soifer VA. Diffraction investigation of geometric-optical focusators into segment. Optik - International Journal for Light and Electron Optics, 1994; 96(4): 158162.

19. Doskolovich LL, Kazanskiy NL, Soifer VA, Tzaregorodtzev AYe. Analysis of quasiperiodic and geometric optical solutions of the problem of focusing into an axial segment. Optik - International Journal for Light and Electron Optics, 1995; 101(2): 37-41.

20. Doskolovich LL, Kazansky NL, Kharitonov SI, Soifer VA. A method of designing diffractive optical elements focusing into plane areas. Journal of Modern Optics, 1996; 43(7): 1423-1433. DOI: 10.1080/09500349608232815.

21. Doskolovich LL, Kazanskiy NL, Soifer VA, Perlo P, Repetto P. Design of DOEs for wavelength division and focusing. Journal of Modern Optics, 2005; 52(6): 917-926. DOI: 10.1080/09500340512331313953.

22. Doskolovich LL, Moiseev MA, Kazanskiy NL. On using a supporting quadric method to design diffractive optical elements. Computer Optics, 2015; 39(3): 339-346. DOI: 10.18287/0134-2452-2015-39-3-339-346.

23. Doskolovich LL, Golub MA, Kazanskiy NL, Khramov AG, Pavelyev VS, Seraphimovich PG, Soifer VA, Volotovskiy SG. Software on diffractive optics and computer generated holograms. Proceedings of SPIE, 1995; 2363: 278-284. DOI: 10.1117/12.199645.

24. Golovashkin DL, Kasanskiy NL. Solving Diffractive Optics Problem using Graphics Processing Units. Optical Memory and Neural Networks (Information Optics), 2011; 20(2): 85-89. DOI: 10.3103/S1060992X11020019.

25. Golub MA, Kazanskii NL, Sisakyan IN, Soifer VA. Computational experiment with plane optical elements. Optoelectronics, Instrumentation and Data Processing6 1988; 1: 78-89.

26. Khonina SN, Kazanskiy NL, Volotovsky SG. Influence of Vortex Transmission Phase Function on Intensity Distribution in the Focal Area of High-Aperture Focusing System. 
Optical Memory and Neural Networks (Information Optics), 2011; 20(1): 23-42. DOI: 10.3103/S1060992X11010024.

27. Khonina SN, Kazanskii NL, Ustinov AV, Volotovskii SG. The lensacon: nonparaxial effects. Journal of Optical Technology, 2011; 78(11): 724-729. DOI: 10.1364/JOT.78.000724.

28. Kazanskiy NL, Serafimovich PG. Cloud Computing for Nanophotonic Simulations. Lecture Notes in Computer Science, 2013; 7715: 54-67. DOI: 10.1007/978-3-64238250-5_7.

29. Volkov AV, Kazanskiy NL, Moiseev OYu, Soifer VA. A Method for the Diffractive Microrelief Formation Using the Layered Photoresist Growth. Optics and Lasers in Engineering, 1998; 29(4-5): 281-288.

30. Kazanskii NL, Kolpakov VA, Kolpakov AI. Anisotropic Etching of $\mathrm{SiO}_{2}$ in HighVoltage Gas-Discharge Plasmas. Russian Microelectronics, 2004; 3(3): 169-182. DOI: 10.1023/B:RUMI.0000026175.29416.eb.

31. Pavelyev VS, Borodin SA, Kazanskiy NL, Kostyuk GF, Volkov AV. Formation of diffractive microrelief on diamond film surface. Optics \& Laser Technology, 2007; 39(6): 1234-1238. DOI: 10.1016/j.optlastec.2006.08.004.

32. Bezus EA, Doskolovich LL, Kazanskiy NL. Interference pattern formation in evanescent electromagnetic waves using waveguide diffraction gratings. Quantum Electronics, 2011; 41(8): 759-764. DOI: 10.1070/QE2011v041n08ABEH014500.

33. Kazanskiy NL, Kolpakov VA, Podlipnov VV. Gas discharge devices generating the directed fluxes of off-electrode plasma. Vacuum, 2014; 101: 291-297. DOI: 10.1016/j.vacuum.2013.09.014.

34. Abul'khanov SR, Kazanskii NL, Doskolovich LL, Kazakova OY. Manufacture of diffractive optical elements by cutting on numerically controlled machine tools. Russian Engineering Research, 2011; 31(12): 1268-1272. DOI: 10.3103/S1068798X11120033.

35. Volkov AV, Kazanskiy NL, Moiseev OYu, Poletayev SD. Thermal Oxidative Degradation of Molybdenum Films under Laser Ablation. Technical Physics, 2015; 60(2): 265269. DOI: $10.1134 / \mathrm{S} 1063784215020255$.

36. Kazanskiy NL, Moiseev OYu, Poletayev SD. Microprofile Formation by Thermal Oxidation of Molybdenum Films. Technical Physics Letters, 2016; 42(2): 164-166. DOI: $10.1134 / \mathrm{S} 1063785016020085$.

37. Kazanskiy NL, Uspleniev GV, Volkov AV. Fabricating and testing diffractive optical elements focusing into a ring and into a twin-spot. Proceedings of SPIE, 2000; 4316: 193-199. DOI: $10.1117 / 12.407678$.

38. Doskolovich L.L., Kazanskiy NL, Khonina SN, Skidanov RV, Heikkila N, Siitonen S, Turunen J. Design and investigation of color separation diffraction gratings. Applied Optics, 2007; 46(15): 2825-2830. DOI: 10.1364/AO.46.002825.

39. Kazanskiy NL, Skidanov RV. Binary beam splitter. Applied Optics, 2012; 51(14): 2672-2677. DOI: 10.1364/AO.51.002672.

40. Kazanskiy NL. Research \& Education Center of Diffractive Optics. Proceedings of SPIE, 2012; 8410: 84100R. DOI: 10.1117/12.923233.

41. Ignatiev IE, End JV, Ignatieva EV, Pastukhov EA. Mixing in the melt of the solid insoluble particles during production of composite alloys. Proceedings of the conference "Structure and properties of metallic and slag melts", Ekaterinburg, September 22-26, 2008: 108-109 (in Russian).

42. Solomatnikov MS. Development of a device for cladding powders of glass microspheres in the combined mixing of particles. Proceedings of Tula State University. Technical Sciences, 2013; 11: 146-152 (in Russian).

43. Kosachev AF, Kuznetsov IN, Danilov SV, Gutareva N. Technology and production of cellular concrete based on waste of quartz. Bulletin of Siberian State Automobile and Highway Academy, 2013; 3(13): 82-86 (in Russian). 
44. Chernetskaya NA, Kulagina NA, Kantor SA, Shaposhnikov YuA. Dynamics of interaction of particles and the fat of the blade during the mixing process. Siberian Bulletin of Agricultural Sciences, 2012; 2: 66-71 (in Russian).

45. Khamitov RN, Aver'yanov GS, Korchagin AB. Pneumatic shock absorber with an active damping system. Russian Engineering Research, 2009; 29(9): 871-873.

46. Pham TA, Nguyen TZ, Cao WL. Review of the determination coefficient gas damping in microelectronics-mechanical systems. New University. Series: Technical Sciences, 2015; 9-10(43-44): 62-66 (in Russian).

47. Soifer VA, Kazanskiy NL, Abulkhanov SR. Mixer. Patent RF 2,319,432, Publish Date 10.05.2006.

48. Soifer VA, Kazanskiy NL, Strelkov YuS, Dmitriev AYu, Doskolovich LL, Kharitonov SI. Vibrating mixer. Patent RF 2,422,195, Publish Date 21.12.2009.

49. Abulkhanov SR, Kazansky NL, Soifer VA. Damper high frequencies. Patent RF 2,462,630, Publish Date 24.12.2010.

50. Karpeev SV, Pavelyev VS, Khonina SN, Kazanskiy NL, Gavrilov AV, Eropolov VA. Fibre sensors based on transverse mode selection. Journal of Modern Optics, 2007; 54(6): 833-844. DOI: 10.1080/09500340601066125.

51. Egorov AV, Kazanskiy NL, Serafimovich PG. Using coupled photonic crystal cavities for increasing of sensor sensitivity. Computer Optics, 2015; 39(2): 158-162. DOI: 10.18287/0134-2452-2015-39-2-158-162.

52. Borodin SA, Volkov AV, Kazanskii NL. Device for analyzing nanoroughness and contamination on a substrate from the dynamic state of a liquid drop deposited on its surface. Journal of Optical Technology, 2009; 76(7): 408-412. DOI: 10.1364/JOT.76.000408.

53. Kazanskiy NL, Popov SB. Machine Vision System for Singularity Detection in Monitoring the Long Process. Optical Memory and Neural Networks (Information Optics), 2010; 19(1): 23-30. DOI: 10.3103/S1060992X10010042.

54. Kazanskiy NL, Popov SB. Distributed storage and parallel processing for large-size optical images. Proceedings of SPIE, 2012; 8410: 84100I. DOI: 10.1117/12.928441.

55. Kazanskiy NL, Popov SB. The distributed vision system of the registration of the railway train. Computer Optics, 2012; 36(3): 419-428.

56. Kazanskiy NL, Popov SB. Integrated Design Technology for Computer Vision Systems in Railway Transportation. Pattern Recognition and Image Analysis, 2015; 25(2): 215219. DOI: $10.1134 /$ S1054661815020133.

57. Kazanskiy NL, Kharitonov SI, Khonina SN, Volotovskiy SG, Strelkov YuS. Simulation of hyperspectrometer on spectral linear variable filters. Computer Optics, 2014; 38(2): 256-270.

58. Kazanskiy NL, Kharitonov SI, Karsakov AV, Khonina SN. Modeling action of a hyperspectrometer based on the Offner scheme within geometric optics. Computer Optics, 2014; 38(2): 271-280.

59. Kazanskiy NL, Kharitonov SI, Khonina SN. Simulation of a hyperspectrometer based on linear spectral filters using vector Bessel beams. Computer Optics, 2014; 38(4): 770776.

60. Kazanskiy NL, Kharitonov SI, Doskolovich LL, Pavelyev AV. Modeling the performance of a spaceborne hyperspectrometer based on the Offner scheme. Computer Optics, 2015; 39(1): 70-76. DOI: 10.18287/0134-2452-2015-39-1-70-76.

61. Kazanskiy NL, Khonina SN, Skidanov RV, Morozov AA, Kharitonov SI, Volotovskiy SG. Formation of images using multilevel diffractive lens. Computer Optics, 2014; 38(3): 425-434.

62. Doskolovich LL, Kazanskiy NL, Soifer VA, Kharitonov SI, Perlo P. A DOE to form a line-shaped directivity diagram. Journal of Modern Optics, 2004; 51(13): 1999-2005. DOI: $10.1080 / 09500340408232507$. 
63. Aslanov ER, Doskolovich LL, Moiseev MA, Bezus EA, Kazanskiy NL. Design of an optical element forming an axial line segment for efficient LED lighting systems. Optics Express, 2013; 21(23): 28651-28656. DOI: 10.1364/OE.21.028651.

64. Doskolovich LL, Bezus EA, Moiseev MA, Bykov DA, Kazanskiy NL. Analytical source-target mapping method for the design of freeform mirrors generating prescribed 2D intensity distributions. Optics Express, 2016; 24(10): 10962-10971. DOI: 10.1364/OE.24.010962.

65. Bezus EA, Doskolovich LL, Kazanskiy NL, Soifer VA, Kharitonov SI. Design of diffractive lenses for focusing surface plasmons. Journal of Optics, 2010; 12(1): 015001 (7pp). DOI: 10.1088/2040-8978/12/1/015001.

66. Kazanskiy NL, Serafimovich PG, Khonina SN. Harnessing the Guided-Mode Resonance to Design Nanooptical Transmission Spectral Filters. Optical Memory and Neural Networks (Information Optics), 2010; 19(4): 318-324. DOI: 10.3103/ S1060992X10040090.

67. Bykov DA, Doskolovich LL, Soifer VA, Kazanskiy NL. Extraordinary MagnetoOptical Effect of a Change in the Phase of Diffraction Orders in Dielectric Diffraction Gratings. Journal of Experimental and Theoretical Physics, 2010; 111(6): 967-974. DOI: $10.1134 /$ S1063776110120095.

68. Bezus EA, Doskolovich LL, Kazanskiy NL. Scattering suppression in plasmonic optics using a simple two-layer dielectric structure. Applied Physics Letters, 2011; 98(22): 221108. DOI: 10.1063/1.3597620.

69. Bezus EA, Doskolovich LL, Kazanskiy NL, Soifer VA. Scattering in elements of plasmon optics suppressed by two-layer dielectric structures. Technical Physics Letters, 2011; 37(12): 1091-1095. DOI: 10.1134/S1063785011120030.

70. Kazanskiy NL, Serafimovich PG, Khonina SN. Use of photonic crystal cavities for temporal differentiation of optical signals. Optics Letters, 2013; 38(7): 1149-1151. DOI: 10.1364/OL.38.001149.

71. Bezus EA, Doskolovich LL, Kazanskiy NL. Low-scattering surface plasmon refraction with isotropic materials. Optics Express, 2014; 22(11): 13547-13554. DOI: 10.1364/OE.22.013547.

72. Kazanskiy NL, Serafimovich PG. Coupled-resonator optical waveguides for temporal integration of optical signals. Optics Express, 2014; 22(11): 14004-14013. DOI: 10.1364/OE.22.014004.

73. Khonina SN, Savelyev DA, Kazanskiy NL. Vortex phase elements as detectors of polarization state. Optics Express, 2015; 23(14): 17845-17859. DOI: 10.1364/OE.23.017845.

74. Soifer VA. Diffractive nanophotonics and advanced information technologies. Herald of the Russian Academy of Sciences, 2014, 84(1): 9-19. 